\title{
The Use of Antidepressants, Anxiolytics, and Hypnotics in People with Type 2 Diabetes and Patterns Associated with Use: The Hoorn Diabetes Care System Cohort
}

\author{
R. Mast, ${ }^{1,2}$ S. P. Rauh, ${ }^{1,3}$ L. Groeneveld, ${ }^{1,3}$ A. D. Koopman, ${ }^{1,3}$ J. W. J. Beulens, ${ }^{1,3,4}$ \\ A. P. D. Jansen, ${ }^{1,5}$ M. Bremmer, ${ }^{1,6}$ A. A. W. A. van der Heijden, ${ }^{1,5}$ P. J. Elders, ${ }^{1,5}$ \\ J. M. Dekker, ${ }^{1,3}$ G. Nijpels, ${ }^{1,5}$ J. G. Hugtenburg, ${ }^{1,2}$ and F. Rutters ${ }^{1,3}$ \\ ${ }^{1}$ EMGO+ Institute for Health and Care Research, VU Medical Center, Amsterdam, Netherlands \\ ${ }^{2}$ Department of Clinical Pharmacology and Pharmacy, VU Medical Center, Amsterdam, Netherlands \\ ${ }^{3}$ Department of Epidemiology and Biostatistics, VU Medical Center, Amsterdam, Netherlands \\ ${ }_{4}^{4}$ Julius Center for Health Sciences and Primary Care, University Medical Center Utrecht, Utrecht, Netherlands \\ ${ }^{5}$ Department of General Practice and Elderly Care Medicine, VU Medical Center, Amsterdam, Netherlands \\ ${ }^{6}$ Department of Psychiatry, VU Medical Center, Amsterdam, Netherlands
}

Correspondence should be addressed to R. Mast; m.mast@vumc.nl

Received 21 August 2016; Accepted 27 December 2016; Published 23 January 2017

Academic Editor: Jessica J. Jalbert

Copyright (c) 2017 R. Mast et al. This is an open access article distributed under the Creative Commons Attribution License, which permits unrestricted use, distribution, and reproduction in any medium, provided the original work is properly cited.

\begin{abstract}
Objective. With depression being present in approximately $20 \%$ of people with type 2 diabetes mellitus (T2DM), we expect equally frequent prescription of antidepressants, anxiolytics, and hypnotics. Nevertheless, prescription data in people with T2DM is missing and the effect of depression on glycaemic control is contradictory. The aim of this study was to assess the prevalence of antidepressants, anxiolytics, and/or hypnotics use in a large, managed, primary care system cohort of people with T2DM and to determine the sociodemographic characteristics, comorbidities, T2DM medication, and metabolic control associated with its use. Method. The prevalence of antidepressants, anxiolytics, and/or hypnotics use in the years 2007-2012 was assessed in the Hoorn Diabetes Care System Cohort from the Netherlands. Results. From the 7016 people with T2DM, 500 people (7.1\%) used antidepressants only, 456 people (6.5\%) used anxiolytics and/or hypnotics only, and 254 people (3.6\%) used a combination. Conclusion. We conclude that in our managed, primary care system $17 \%$ of all people with T2DM used antidepressants, anxiolytics, and/or hypnotics. Users of antidepressants, anxiolytics, and/or hypnotics were more often female, non-Caucasian, lower educated, and more often treated with insulin.
\end{abstract}

\section{Introduction}

In our current society, depression is present in approximately $20 \%$ of the people with type 2 diabetes mellitus (T2DM), twice as many when compared to the nondiabetic population [1]. Two recent meta-analyses have shown that depression increases the risk of developing T2DM and vice versa [2, 3]. Similar reciprocal associations have been observed for anxiety, sleep disorders, and T2DM $[4,5]$.

Depression, anxiety, and/or sleep problems are diagnosed using the Diagnostic and Statistical Manual of Mental Disorders IV (DSM-IV) [6] and are treated with psychotherapy or pharmacotherapy when the patient is unresponsive to the former [7]. First choice treatment is psychotherapy, while pharmacotherapy may possibly lead to poorer glycaemic control. However, studies on the effect of depression/pharmacotherapy on glycaemic control have been contradictory [8-10]. Despite the cautious treatment regimes, in Western society, antidepressants, anxiolytics, and hypnotics are by far the most often prescribed drugs $[10,11]$ : in the general population $6 \%$ are prescribed antidepressants and $7.5-9.9 \%$ are prescribed anxiolytics and/or hypnotics $[8,12]$.

While the prevalence of depression, anxiety, and/or sleep disorders in people with T2DM is high $(20 \%)[13,14]$, 
we expect equally frequent prescription of antidepressants, anxiolytics, and hypnotics. One study from Finland reported that antidepressant use among men and women who develop T2DM was 2 times higher than the use in nondiabetic individuals [15]. Nevertheless, to our knowledge prevalence data of antidepressants, anxiolytics, and hypnotics use in people with T2DM are scarce. This may be due to the fact that people with T2DM are often excluded from trials on depression treatment [16]. In addition, all previous studies [5-8, 1113] on the coincidence with T2DM assessed depression, anxiety, and/or sleep disorders by interview or questionnaire, with no information on pharmacological treatment. Our first aim is therefore to assess the prevalence of antidepressants, anxiolytics, and hypnotics use in a population-based cohort of people with T2DM.

Patterns of antidepressants, anxiolytics, and/or hypnotics use are well known in the general population [11, 17]. Antidepressants, anxiolytics, and/or hypnotics are more often prescribed to women, compared to men [11]. Furthermore, lower education level, older age, and non-Caucasian ethnicity have been associated with use of antidepressants, anxiolytics, and/or hypnotics [11]. While people with T2DM often have a lower level of education and higher age, we expect higher levels of antidepressants, anxiolytics, and/or hypnotics use in people with T2DM compared with the general population $[17,18]$. Up until now the patterns of use of antidepressants, anxiolytics, and/or hypnotics in people with T2DM have not been investigated.

However, identifying and treating depression, anxiety, and sleep problems has become an increasingly important component of the diabetes management. Nevertheless, we do not know if people with T2DM are more often treated with antidepressants, anxiolytics, and/or hypnotics and information on the determinants of use.

Therefore, the overall aim of this study was to assess the prevalence of antidepressants, anxiolytics, and/or hypnotics use in a large, managed, primary care system cohort of people with T2DM and to determine the sociodemographic characteristics, comorbidities, T2DM medication, and metabolic control associated with its use.

\section{Methods and Materials}

\subsection{Data Source}

2.1.1. Hoorn Diabetes Care System Cohort. Data were derived from the Hoorn Diabetes Care System (DCS) Cohort, a prospective using clinical care data, which is described in detail elsewhere [19]. In short, the DCS Cohort uses a centrally organized managed care plan for treatment of people with T2DM with contracted health care providers. The organization of the DCS is therefore responsible for all the quality of diabetes care in the region of West-Friesland in the Netherlands, a region with about 200,000 inhabitants. The DCS Cohort encompasses the care provided by a patient's primary care physician and secondary care, according to the Dutch treatment guidelines for T2DM [20]. The data from the annual assessment of the people with T2DM, which is organized centrally by the DCS, was used in this study.
Starting from 1st of October 1996, all the people from the catchment region who have been diagnosed with T2DM enter our prospective dynamic DCS Cohort, which currently holds 9118 people with T2DM with at least one measurement at the 31st of December 2012. For each patient, the year of entry to the DCS Cohort was considered to be the baseline measurement and the reported annual data will therefore contain data from people with incident T2DM and prevalent T2DM. We estimated the point prevalence of the use of antidepressants, anxiolytics, and hypnotics over each year and showed in more detail the participant characteristics in the year 2011, as that year the digital registration was implemented and thus the dataset most complete. For our current study, we had medication use data of all patients included and we excluded only patients who did not visit the DCS in the year $2011(n=2102)$, which resulted in a cohort of 7016 people with T2DM. The DCS Cohort has anonymous computer records and people with T2DM were informed on the use of these records for research purposes. The characteristics of the Hoorn Diabetes Care System Cohort in the year 2011 are described in Table 1. The Medical Ethical Committee of the VU University Medical Center has approved this study.

2.1.2. The New Hoorn Study Cohort, General Population. The New Hoorn Study is a population-based cohort, which is representative for the general Dutch population. In short, in 2006-2007, a population-based survey was carried out in the Dutch city of Hoorn, a city in the middle of the West-Friesland region. The eligible population consisted of 6180 men and women, aged 40-75 years, that were randomly selected from the municipal registry. Of the eligible participants, $45 \%$ agreed to participate, resulting in a population-based cohort of 2807 participants. As this population-based cohort is sampled from the general population within the catchment area of the Diabetes Care System Cohorts, is about the same age ( $\max 10$ years difference), adheres to the same level of care, and shares a study location, nurses, and study protocols, we believe it is the optimal comparison cohort. The characteristics of the population-based cohort in the year 2007 are described in Supplement Table 1 in Supplementary Material available online at https://doi.org/10.1155/2017/5134602. In short, this population-based cohort was aged $53.4 \pm 6.7$ years; similarly to the T2DM cohort about $50 \%$ was male, and, however, as it is a population-based cohort only $7.1 \%$ had prevalent diabetes according to the $\mathrm{WHO}$ criteria.

2.2. Measurements. At baseline and each year following, when the patients visit the Diabetes Care System, the following measures are taken.

2.2.1. Medication. Information on current medication use was registered yearly at the annual visit by checking the dispensing labels of the medication brought in by people with T2DM.

(1) Antidepressants, anxiolytics, and hypnotics: we categorized antidepressants, anxiolytics, and hypnotics 
TABLE 1: Patients characteristics and prevalence of antidepressants, anxiolytics, and/or hypnotics use in the year 2011 from the Hoorn Diabetes Care System Cohort.

\begin{tabular}{|c|c|c|}
\hline & & Percentage missing data \\
\hline Number of patients $(n)$ & 7016 & \\
\hline Male (\%) & 52.2 & - \\
\hline Age (years) & $66.3 \pm 11.7(66.6,15.6)$ & - \\
\hline $\mathrm{HbAlc}(\mathrm{mmol} / \mathrm{mol}$ and \%) & $52(6.9) \pm 1.1(49,1.0)$ & $1.8 \%$ \\
\hline $\operatorname{BMI}\left(\mathrm{kg} / \mathrm{m}^{2}\right)$ & $30.2 \pm 5.4(29.3,6.7)$ & $4.6 \%$ \\
\hline Diabetes duration (years) & $7.3 \pm 6.6(6.0,9.0)$ & $0.3 \%$ \\
\hline Onset age of diabetes (years) & $58.1 \pm 12.1(59.0,16.0)$ & $0.3 \%$ \\
\hline Ethnicity (\% Caucasian) & 77.5 & 15 \\
\hline Education (\%) & & 5.4 \\
\hline Low & 43.8 & \\
\hline Middle & 37.0 & \\
\hline High & 13.8 & \\
\hline Marriage status (\%) & & 27.7 \\
\hline Married & 45.5 & \\
\hline Unmarried & 5.0 & \\
\hline Divorced & 0.9 & \\
\hline Single & 7.7 & \\
\hline Widowed & 13.2 & \\
\hline Only antidepressants use (\%) & 7.1 & - \\
\hline Only anxiolytics and/or hypnotics use (\%) & 6.5 & - \\
\hline Combination use (antidepressants and anxiolytics/hypnotics) (\%) & 3.6 & - \\
\hline Comorbidities (\%) & 16.5 & - \\
\hline Diet only (\%) & 17.7 & - \\
\hline Oral glucose lowering agents use only (\%) & 60.1 & - \\
\hline Insulin use (\%) & 22.1 & - \\
\hline
\end{tabular}

Data as mean \pm standard deviation or median (interquartile range). BMI: body mass index; HbAlc: glycated hemoglobin; SD: standard deviation. For continuous variables, we reported the mean $+\mathrm{SD}$ as well as the median and the IQR.

based on their ATC codes, namely, N06A for antidepressants, N05B for anxiolytics, and N05C for hypnotics and sedatives. Since the division between anxiolytics and hypnotics depends on the indication, which we did not have, we combined anxiolytics and hypnotics use into one group.

People using diazepam enemas and/or hydroxyzine were not categorized as anxiolytic users, because diazepam enemas are more often prescribed for the emergency management of epileptic seizures and hydroxyzine is often prescribed against allergies. Diazepam enemas and hydroxyzine uses were therefore not included in this analysis.

People with T2DM were divided into 4 groups: (1) no use of antidepressants, anxiolytics, and/or hypnotics (people who are not taking the medications of interest at the time of the annual consultation); (2) only use of antidepressants; (3) only use of anxiolytics and/or hypnotics; (4) combined use of antidepressants and anxiolytics and/or hypnotics.

(2) T2DM medication: we defined three groups, based on ATC codes: diet only (no medication), insulin analogues (A10A), and oral glucose lowering agents
(OGA, A10B). The OGA group contains the following OGAs: metformin, sulphonylurea, thiazolidinediones, alfa glucosidase inhibitors, DPP4 inhibitors, meglitinides, and GLP-1 receptor agonists. Most patients using insulin analogues were using as well OGA.

2.2.2. Sociodemographic Patterns. During the annual visit to the research center, several sociodemographic factors were assessed in an interview, performed by the research nurse. Age and gender were self-reported. Education level was assessed using the question: "What is your highest completed educational level?" The response alternatives were 1: primary education, 2: secondary education, practical training, 3: prevocational secondary education, 4: vocational training, 5: general secondary education or preuniversity education, 6: professional university education, and 7: university. Educational level was divided into 3 groups: low (levels 1-2), middle (levels 3-5), and high (levels 6-7). Ethnicity was self-reported based on the questions: "Indicate country of birth of your biological father and mother."

2.2.3. Comorbidities. Information on history of cardiovascular disease, including myocardial infarction, transient ischaemic attack, and stroke was self-reported. 
2.2.4. HbAlc Levels. HbAlc levels (\%) were assessed from a fasted blood sample, using DCCT standardized reversedphase cation exchange chromatography (HA 8160 analyzer, Menarini, Florence, Italy). HbAlc levels were detected using dual-wavelength colorimetric method (415-500). The intraassay coefficient of variation was $0.6 \%$ at a mean level of $4.9 \%$ and the interassay CV was $0.8 \%$ at a mean level of $5.5 \%$.

2.2.5. Weight and Height. Weight $(\mathrm{kg})$ and height $(\mathrm{cm})$ were measured annually during the visit in the research center, while barefoot and wearing light clothing. BMI $\left(\mathrm{kg} / \mathrm{m}^{2}\right)$ was calculated by weight in kilograms divided by the square of height in meters.

2.3. Statistical Analysis. The patients characteristics of users and nonusers were reported as mean and standard deviation for continuous variables and, in the case of a skewed distribution, the medium with 25 th and 75 th percentile (diabetes duration).

We compared patterns of users and nonusers, using descriptive summary statistics, including One-Way ANOVA for mean levels, with Chi-square tests (linear-by-linear association) for proportions and Kruskal-Wallis test for median levels.

Subsequently, a model was created using multivariate logistic backward regression analysis. In this analysis we assessed which available patient and disease determinants at baseline were associated with antidepressants, anxiolytics, and/or hypnotics use. All determinants were entered simultaneously using backward elimination method, leading to a model including only significant $(p<0.5)$ determinants. Finally, we reported data on the prevalence of antidepressants, anxiolytics, and/or hypnotics use in the general population.

Statistical analyses were performed with SPSS version 20.0 (SPSS Inc., Chicago, IL) and a two-sided $p$ value below 0.05 was considered statistically significant.

\section{Results}

3.1. Population. The population characteristics of the Hoorn Diabetes Care System Cohort of people with T2DM in the year 2011 are described in Table 1 and for the years 20072012 in Supplementary Table 2. In 2011, the cohort consisted of an equal amount of women and men with T2DM, with a mean age of 66.3 years (SD 11.7) and $22.5 \%$ of non-Caucasian ethnicity, while $40 \%$ had a low level of education. Most people with T2DM in the cohort used OGAs $(60.1 \%)$ or insulin (combined with OGA (22.1\%)) and the majority was overweight $\left(30.2 \mathrm{~kg} / \mathrm{m}^{2}\right.$, SD 5.4), but well controlled as shown by a mean $\mathrm{HbAlc}$ level of $52 \mathrm{mmol} / \mathrm{mol}$ (6.9\%).

3.2. Antidepressants and Anxiolytics and/or Hypnotics Use. In our cohort of people with T2DM, the prevalence of antidepressants, anxiolytics, and/or hypnotics use was $17.2 \%$ : with $7.1 \%$ using an antidepressant only, $6.5 \%$ using anxiolytic and/or hypnotic only, and $3.6 \%$ using a combination of antidepressants and anxiolytics and/or hypnotics. Figure 1 showed the prevalence of antidepressants, anxiolytics, and/or hypnotics use between 2007 and 2012. In the total population, the prevalence of antidepressants use was 5.4\% in 2007 and increased to $7.3 \%$ in 2012. Also, the prevalence of anxiolytics and/or hypnotics use increased, starting at $5.8 \%$ and increasing to $6.5 \%$ in 2012 . With regard to patients using a combination of antidepressants and anxiolytics and/or hypnotics, the prevalence of use increased from $2.4 \%$ in 2007 to $3.3 \%$ in 2012 .

3.3. Sociodemographic Patterns. Table 2 depicts the sociodemographic patterns stratified for antidepressant, anxiolytics, and/or hypnotics users versus nonusers in the year 2011. Compared to nonusers, users were more often female: $44.3 \%$ of the nonusers were female, while $61.8 \%-74.8 \%$ of users were female $(p<0.001)$. We also observed differences in ethnicity with $21.2 \%$ of the nonusers being non-Caucasian versus $26.2 \%-29.8 \%$ of the users $(p<0.001)$ as well as education level, with $42.7 \%$ of nonusers having a lower education level versus $48.0 \%-52.8 \%$ of users $(p<0.001)$. Further, compared to nonusers, those on anxiolytics and/or hypnotics $(p<0.001)$ as well as users of antidepressants and anxiolytics/hypnotics $(p<0.02)$ were significantly older. No significant age differences were observed in the users of antidepressants only.

3.4. Comorbidities. Nonusers had less comorbidities (myocardial infarction, transient ischaemic attack, and stroke), compared to people with T2DM on anxiolytics and/or hypnotics (15.4\% versus $26.8 \%, p<0.001)$. No differences in comorbidities were observed in nonusers versus antidepressant or anxiolytics and/or hypnotics users.

3.5. T2DM Treatment and Glycaemic Control. Finally, compared to nonusers, those people using antidepressants more often used insulin as T2DM treatment $(21.5 \%$ versus $27.2 \%, p<0.001)$. No differences were observed in T2DM treatment between nonusers and anxiolytics and/or hypnotics users. Additionally, no significant differences were observed in continuous HbAlc or cut-off variables for HbAlc levels $(\geq 53 \mathrm{mmol} / \mathrm{mol}$ ) between users and nonusers. With regard to BMI, compared to nonusers, users of antidepressants had significant higher BMI levels compared to nonusers $\left(31.2 \mathrm{~kg} / \mathrm{m}^{2}\right.$ versus $\left.30.1 \mathrm{~kg} / \mathrm{m}^{2}, p<0.001\right)$.

3.6. Antidepressants, Anxiolytics, and/or Hypnotics Users. Antidepressants, anxiolytics, and hypnotics users had a statistically significantly higher likelihood of being women and non-Caucasian and have more often comorbidities, compared to nonusers of antidepressants, anxiolytics, and hypnotics (Table 3).

3.7. Antidepressants, Anxiolytics, and/or Hypnotics Users in the General Population. In our sample from the general population, we observed that the prevalence of antidepressant use is $1.9 \%$ and $<1.0 \%$ for anxiolytics and hypnotics (Supplement Table 1). 


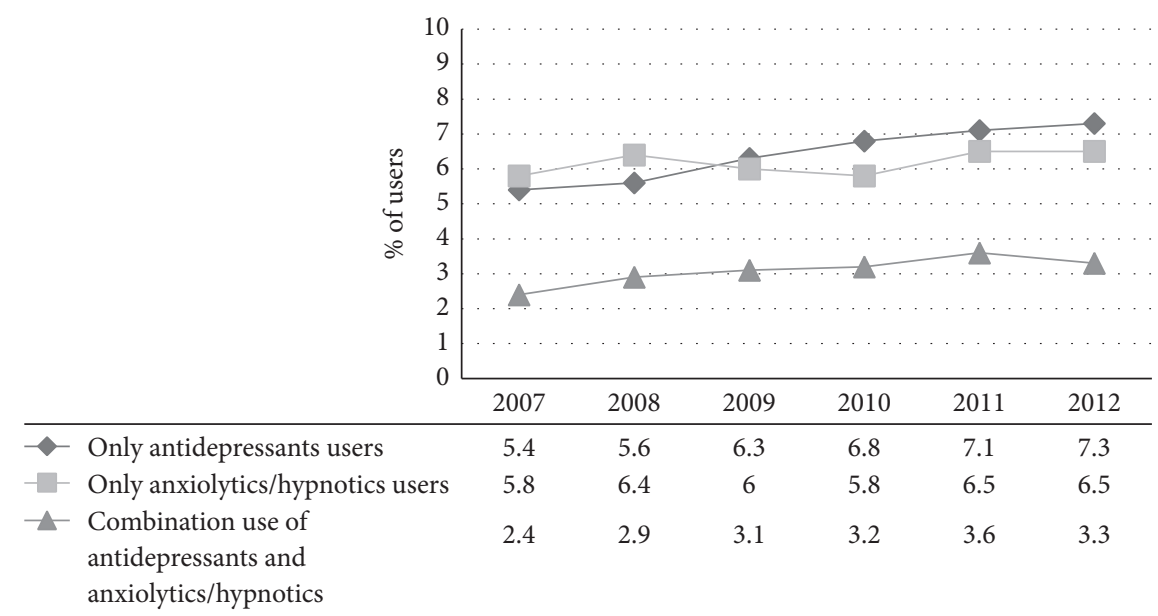

FIGURE 1: Prevalent use of antidepressants, anxiolytics, and/or hypnotics for the years 2007-2012 in the Hoorn Diabetes Care System Cohort.

TABLE 2: Patients characteristics stratified by antidepressant, anxiolytics, and/or hypnotics use in the Hoorn Diabetes Care System Cohort in the year $2011(n=7016)$.

\begin{tabular}{|c|c|c|c|c|}
\hline & Nonusers & $\begin{array}{c}\text { Antidepressants } \\
\text { users }\end{array}$ & Anxiolytics/hypnotics users & $\begin{array}{c}\text { Combined use of } \\
\text { antidepressants and } \\
\text { anxiolytics/hypnotics }\end{array}$ \\
\hline \multicolumn{5}{|c|}{ General characteristics } \\
\hline $\begin{array}{l}\text { Number of patients }(n) \\
\text { (\% of total number of } \\
\text { patients) }\end{array}$ & $5806(82.8)$ & $500(7.1)$ & $456(6.5)$ & $254(3.6)$ \\
\hline Male (\%) & 55.7 & $38.2^{*}$ & $38.2^{*}$ & $25.2^{*}$ \\
\hline Age (years) & $65.9 \pm 11.5$ & $64.7 \pm 13.0$ & $71.7 \pm 11.4^{*}$ & $68.1 \pm 13.2^{*}$ \\
\hline $\mathrm{HbAlc}(\mathrm{mmol} / \mathrm{mol}(\%))$ & $52(6.9) \pm 1.1$ & $52(6.9) \pm 1.1$ & $51(6.8) \pm 0.9$ & $52(6.9) \pm 1.0$ \\
\hline $\mathrm{BMI}\left(\mathrm{kg} / \mathrm{m}^{2}\right)$ & $30.1 \pm 5.4$ & $31.2 \pm 5.7^{*}$ & $29.9 \pm 5.2$ & $31.4 \pm 5.4^{*}$ \\
\hline Diabetes duration (years) & $5.9(2.0-10.5)$ & $5.0(1.8-10.2)$ & $7.0(2.8-11.70)^{*}$ & $6.0(2.8-10.6)$ \\
\hline \multicolumn{5}{|c|}{ Sociodemographic characteristics } \\
\hline Ethnicity (\% Caucasian) & 78.8 & $73.8^{*}$ & $70.2^{*}$ & $70.9^{*}$ \\
\hline \multicolumn{5}{|l|}{ Education (\%) } \\
\hline Low & 44.7 & $51.7^{*}$ & $54.7^{*}$ & $60.1^{*}$ \\
\hline Middle & 39.9 & $38.8^{*}$ & $34.5^{*}$ & $30.0^{*}$ \\
\hline High & 15.5 & $9.5^{*}$ & $10.8^{*}$ & $9.9^{*}$ \\
\hline \multicolumn{5}{|c|}{ Comorbidities } \\
\hline Comorbidities (\%) & 15.4 & 17.2 & $26.8^{*}$ & 20.1 \\
\hline \multicolumn{5}{|c|}{ Diabetes treatment } \\
\hline Diet only (\%) & 18.2 & $16.6^{*}$ & 14.9 & 14.2 \\
\hline $\begin{array}{l}\text { Oral glucose lowering } \\
\text { agents use only (\%) }\end{array}$ & 60.3 & $56.2^{*}$ & 62.3 & 60.2 \\
\hline Insulin use (\%) & 21.5 & $27.2^{*}$ & 22.8 & 25.6 \\
\hline
\end{tabular}

BMI: body mass index; HbAlc: glycated hemoglobin; SD: standard deviation.

${ }^{*}$ Significantly different from no antidepressant/anxiolytics/hypnotics users. It is possible that patients are using insulin in combination with oral glucose lowering agents.

\section{Discussion}

The aim of this study was to assess the prevalence of antidepressants, anxiolytics, and/or hypnotics use in a large, managed, primary care system of people with T2DM and to determine the sociodemographic characteristics, comorbidities, T2DM medication, and metabolic control associated with its use. We observed that the total prevalence of use was $17.2 \%$ in our cohort of people with T2DM. The prevalence of use was $7.1 \%$ for antidepressants, $6.5 \%$ for anxiolytics 
TABLE 3: Multivariate regression analyses determining patient characteristics of antidepressants, anxiolytics, and hypnotics use versus no antidepressants, anxiolytics, and hypnotics use.

\begin{tabular}{lcr}
\hline & Univariate OR (95\% CI) & Multivariate OR (95\% CI) \\
\hline Sex (female) & $2.29(2.02-2.61)^{*}$ & $2.37(2.08-2.70)$ \\
Age (years) & $1.02(1.01-1.02)^{*}$ & \\
HbAlc level (mmol/mol) & $0.98(0.92-1.04)$ & $1.49(1.28-1.74)^{*}$ \\
Comorbidity (myocardial infarction, transient ischaemic attack, stroke) & $1.02(1.01-1.03)^{*}$ & $(1.40-1.93)$ \\
BMI $\left(\mathrm{kg} / \mathrm{m}^{2}\right)$ & $0.63(0.55-0.71)$ & $0.65(0.57-0.74)$ \\
Ethnicity (non-Caucasian) & & \\
\hline
\end{tabular}

Estimated are odds ratios (OR) with $95 \%$ confidence interval. $*$ indicates a significant association $(p<0.05)$. The univariate model shows the determinants with $p$ values $<0.05$. The multivariate model shows the final model after backward selection, including variables with $p$ values $<0.05$.

and/or hypnotics, and $3.6 \%$ for the combination of these medications. In concordance with our expectations, the prevalence of antidepressants, anxiolytics, and/or hypnotics use was higher in people with T2DM, compared to the general population in which less than $2 \%$ used antidepressants, anxiolytics, and/or hypnotics $[8,12]$. The general population cohort is from the same catchment area as the people with T2DM, but slightly younger. We therefore expect that overall the difference between the general population and people with T2DM would be slightly smaller, but still significant.

In concordance with studies from the literature in the general population, we observed that people with T2DM using antidepressants, anxiolytics, and/or hypnotics were more often female, older, non-Caucasian, and having a lower level of education, compared to nonusers [11, 12, 21]. Several possible reasons have been offered in literature; first women more often suffer from anxiety and depressive disorders, compared to men [22]. Second, women are more likely to use health services for mental problems and thus depression will more often be diagnosed and treated in women [23].

In contrast to earlier research in elderly people with T2DM, we did not observe more comorbidities in users of antidepressants [24, 25]. An explanation for this may be that our cohort was relatively younger and healthier and metabolically well-controlled. We did however observe that anxiolytics and/or hypnotics users had more comorbidities compared to nonusers. This is in accordance with literature in the general population [26].

Furthermore, we were the first to observe with regard to T2DM medication that people with T2DM using antidepressants were more frequently treated with insulin, compared to non-insulin users. This is in accordance with other literatures on the association between depression and T2DM [27] in that it may reflect disease progression. Insulin-treated people with T2DM often have a longer disease history, including poorer glycaemic control and chance on comorbidities $[27,28]$.

Finally, with regard to metabolic status, no differences in HbAlc level were found between users and nonusers. Earlier studies reported contradictory findings on the effects of antidepressants, anxiolytics, and/or hypnotics use on HbAlc levels [29, 30]. Two longitudinal studies in people with T2DM and one meta-analysis from studies in the general population reported that depression was associated with poorer glycaemic control $[29,30]$, while one study reported a difference of $6 \mathrm{mmol} / \mathrm{mol}(0.5 \%)$ in $\mathrm{HbAlc}$ levels when comparing people with T2DM with and without depressive symptoms [13]. However, another study observed no differences in glycaemic control [14]. Our results support the earlier null-findings; the difference with studies that did find an association may be explained by cohort differences; we are one of the few to have an unselected, population-based cohort of people with T2DM. Finally, longitudinal studies are needed to study the metabolic consequences of these types of medication in people with T2DM.

This study has several limitations that need to be discussed. First of all, we lack information about indication and therefore we decided to combine the anxiolytics and hypnotics into one group. Several anxiolytics, such as oxazepam, can be prescribed in case of anxiety, but also in case of sleep disorders. Further, antidepressants can be prescribed for other disorders than depression alone (e.g., neuropathic pain), but also in cases of anxiety. Also, people may be afflicted by the disease but not have been diagnosed. Finally, we do not have details on psychiatric comorbidities or the onset of the condition with respect to T2DM. Therefore, our current study is not informative on disease prevalence and on the causal effect of medication or the disorder itself on T2DM. We therefore need longitudinal research in large cohorts of people with T2DM, to study the effect of antidepressants, anxiolytics, and hypnotics use on glycaemic control. Another limitation is the absence of data on physical activities and social environment.

The strengths of our study are that we were the first to investigate and report on the prevalence of antidepressants, anxiolytics, and/or hypnotics use, as well as differences in sociodemographic, comorbidities, T2DM medication, and metabolic status between users and nonusers in people with T2DM. In addition, we conducted this study in large $(n>$ 5000) population from routine care, which represented all people from a certain catchment area in care for their T2DM, thereby omitting possible selection bias. All information has been accurately registered as part of regular care and therefore provides a unique care-based T2DM cohort.

We conclude that in our managed, primary care system $17 \%$ of all people with T2DM used antidepressants, anxiolytics, and/or hypnotics. Users of antidepressants, anxiolytics, and/or hypnotics were more often female, non-Caucasian, lower educated, and more often treated with insulin. 


\section{Additional Points}

Novelty Statement. (i) Compared to the prevalence in the general population, use of antidepressants, anxiolytics, and/or hypnotics was only slightly higher in people with T2DM. (ii) No differences in comorbidities and HbAlc were observed between users and nonusers of antidepressants, anxiolytics, and/or hypnotics. (iii) Users of antidepressants, anxiolytics, and/or hypnotics were more frequently treated with insulin.

\section{Competing Interests}

The authors declare that there are no competing interests regarding the publication of this paper.

\section{Authors' Contributions}

R. Mast and F. Rutters researched data and wrote the manuscript. S. P. Rauh and A. D. Koopman researched data and reviewed and edited the manuscript. J. G. Hugtenburg, L. Groeneveld, A. P. D. Jansen, A. A. W. A. van der Heijden, M. Bremmer, P. J. Elders, G. Nijpels, and J. M. Dekker reviewed and edited the manuscript. F. Rutters is the guarantor of this work and, as such, had full access to all the data in the study and takes responsibility for the integrity of the data and the accuracy of the data analysis.

\section{Acknowledgments}

This study has been made possible by collaboration with the Diabetes Care System West-Friesland. The authors thank all general practitioners in the West-Friesland region for their obliging contributions to the study. They also thank the research assistants and staff of the Hoorn Diabetes Care System for the enormous amount of work they did in collecting all of the data.

\section{References}

[1] S. Ali, M. A. Stone, J. L. Peters, M. J. Davies, and K. Khunti, "The prevalence of co-morbid depression in adults with Type2 diabetes: a systematic review and meta-analysis," Diabetic Medicine, vol. 23, no. 11, pp. 1165-1173, 2006.

[2] B. Mezuk, W. W. Eaton, S. Albrecht, and S. H. Golden, "Depression and type 2 diabetes over the lifespan: a metaanalysis," Diabetes Care, vol. 31, no. 12, pp. 2383-2390, 2008.

[3] M. J. Knol, J. W. R. Twisk, A. T. F. Beekman, R. J. Heine, F. J. Snoek, and F. Pouwer, "Depression as a risk factor for the onset of type 2 diabetes mellitus. A meta-analysis," Diabetologia, vol. 49, no. 5, pp. 837-845, 2006.

[4] A. E. Mesas, P. Guallar-Castillón, E. López-García et al., "Sleep quality and the metabolic syndrome: the role of sleep duration and lifestyle," Diabetes/Metabolism Research and Reviews, vol. 30, no. 3, pp. 222-231, 2014.

[5] A. Nouwen, K. Winkley, J. Twisk et al., “Type 2 diabetes mellitus as a risk factor for the onset of depression: a systematic review and meta-analysis," Diabetologia, vol. 53, no. 12, pp. 2480-2486, 2010 .
[6] E. M. Van Weel-Baumgarten, M. G. Van Gelderen, H. G. L. M. Grundmeijer et al., "NHG Standaard Depressie M44," Huisarts en Wetenschap, vol. 55, no. 6, pp. 252-259, 2012.

[7] N. J. Wolf and D. R. Hopko, "Psychosocial and pharmacological interventions for depressed adults in primary care: a critical review," Clinical Psychology Review, vol. 28, no. 1, pp. 131-161, 2008.

[8] G. Verweij and M. Houben-Van Herten, Bevolkingstrends 2013: Depressiviteit en Antidepressiva in Nederland. Centraal Bureau voor Statistiek, Centraal Bureau voor Statistiek, 2013.

[9] D. F. Kripke, R. D. Langer, and L. E. Kline, "Hypnotics' association with mortality or cancer: A Matched Cohort Study," BMJ Open, vol. 2, no. 1, Article ID e000850, 2012.

[10] M. Olfson and S. C. Marcus, "National patterns in antidepressant medication treatment," Archives of General Psychiatry, vol. 66, no. 8, pp. 848-856, 2009.

[11] C. M. Sonnenberg, E. J. M. Biennali, D. J. H. Deeg, H. C. Comijs, W. Van Tilburg, and A. T. F. Beekman, "Ten-year trends in benzodiazepine use in the Dutch population," Social Psychiatry and Psychiatric Epidemiology, vol. 47, no. 2, pp. 293-301, 2012.

[12] C. Huerta, V. Abbing-Karahagopian, G. Requena et al., "Exposure to benzodiazepines (anxiolytics, hypnotics and related drugs) in seven European electronic healthcare databases: a cross-national descriptive study from the PROTECT-EU Project," Pharmacoepidemiology and Drug Safety, vol. 25, pp. 56-65, 2016.

[13] H. Baumeister, N. Hutter, and J. Bengel, "Psychological and pharmacological interventions for depression in patients with diabetes mellitus: an abridged Cochrane review," Diabetic Medicine, vol. 31, no. 7, pp. 773-786, 2014.

[14] T. Roy and C. E. Lloyd, "Epidemiology of depression and diabetes: a systematic review," Journal of Affective Disorders, vol. 142, pp. S8-S21, 2012.

[15] M. Kivimäki, A. G. Tabák, D. A. Lawlor et al., "Antidepressant use before and after the diagnosis of type 2 diabetes," Diabetes Care, vol. 33, no. 7, pp. 1471-1476, 2010.

[16] R. I. Holt, M. de Groot, and S. H. Golden, "Diabetes and depression," Current Diabetes Reports, vol. 14, no. 6, article no. 491, 2014.

[17] P. Demakakos, M. Marmot, and A. Steptoe, "Socioeconomic position and the incidence of type 2 diabetes: the ELSA study," European Journal of Epidemiology, vol. 27, no. 5, pp. 367-378, 2012.

[18] J. Hwang and C. Shon, "Relationship between socioeconomic status and type 2 diabetes: results from Korea National Health and Nutrition Examination Survey (KNHANES) 2010-2012," BMJ Open, vol. 4, no. 8, Article ID e005710, 2014.

[19] H. Zavrelova, T. Hoekstra, M. Alssema et al., "Progression and regression: distinct developmental patterns of diabetic retinopathy in patients with type 2 diabetes treated in the Diabetes Care System West-Friesland, the Netherlands," Diabetes Care, vol. 34, no. 4, pp. 867-872, 2011.

[20] G. E. H. M. Rutten, W. J. C. De Grauw, G. Nijpels et al., NHG Standaard Diabetes Type 2, 2013.

[21] E. Piek, B. J. Kollen, K. Van Der Meer, B. W. J. H. Penninx, and W. A. Nolen, "Maintenance use of antidepressants in dutch general practice: non-guideline concordant," PLOS ONE, vol. 9, no. 5, 2014.

[22] A. Boyd, S. Van de Velde, M. Pivette et al., "Gender differences in psychotropic use across Europe: Results From A Large Crosssectional, Population-based Study," European Psychiatry, vol. 30, no. 6, pp. 778-788, 2015. 
[23] V. Kovess-Masfety, A. Boyd, S. van de Velde et al., "Are there gender differences in service use for mental disorders across countries in the european union? Results from the EU-world mental health survey," Journal of Epidemiology and Community Health, vol. 68, no. 7, pp. 649-656, 2014.

[24] F. Pouwer, A. T. F. Beekman, G. Nijpels et al., "Rates and risks for co-morbid depression in patients with Type 2 diabetes mellitus: results from a community-based study," Diabetologia, vol. 46, no. 7, pp. 892-898, 2003.

[25] R. J. Anderson, K. E. Freedland, R. E. Clouse, and P. J. Lustman, "The prevalence of comorbid depression in adults with diabetes: a meta-analysis," Diabetes Care, vol. 24, no. 6, pp. 1069-1078, 2001.

[26] M. D. Pawaskar, V. N. Joish, F. T. Camacho, R. S. Rasu, and R. Balkrishnan, "The influence of co-morbidities on prescribing pharmacotherapy for insomnia: evidence from US national outpatient data 1995-2004," Journal of Medical Economics, vol. 11, no. 1, pp. 41-56, 2008.

[27] N. Hermanns, B. Kulzer, M. Krichbaum, T. Kubiak, and T. Haak, "Affective and anxiety disorders in a German sample of diabetic patients: prevalence, comorbidity and risk factors," Diabetic Medicine, vol. 22, no. 3, pp. 293-300, 2005.

[28] R. Mast, A. P. D. Jansen, I. Walraven et al., "Time to insulin initiation and long-term effects of initiating insulin in people with type 2 diabetes mellitus: The Hoorn Diabetes Care System Cohort Study," European Journal of Endocrinology, vol. 174, no. 5, pp. 563-571, 2016.

[29] L. Fisher, M. M. Skaff, J. T. Mullan, P. Arean, R. Glasgow, and U. Masharani, "A longitudinal study of affective and anxiety disorders, depressive affect and diabetes distress in adults with type 2 diabetes," Diabetic Medicine, vol. 25, no. 9, pp. 1096-1101, 2008.

[30] M. Bot, F. Pouwer, P. De Jonge, C. J. Tack, P. H. L. M. GeelhoedDuijvestijn, and F. J. Snoek, "Differential associations between depressive symptoms and glycaemic control in outpatients with diabetes," Diabetic Medicine, vol. 30, no. 3, pp. e115-e122, 2013. 


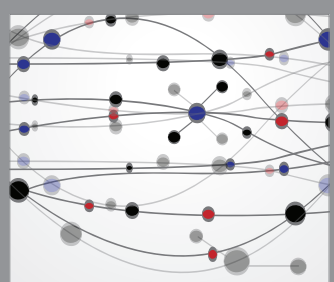

The Scientific World Journal
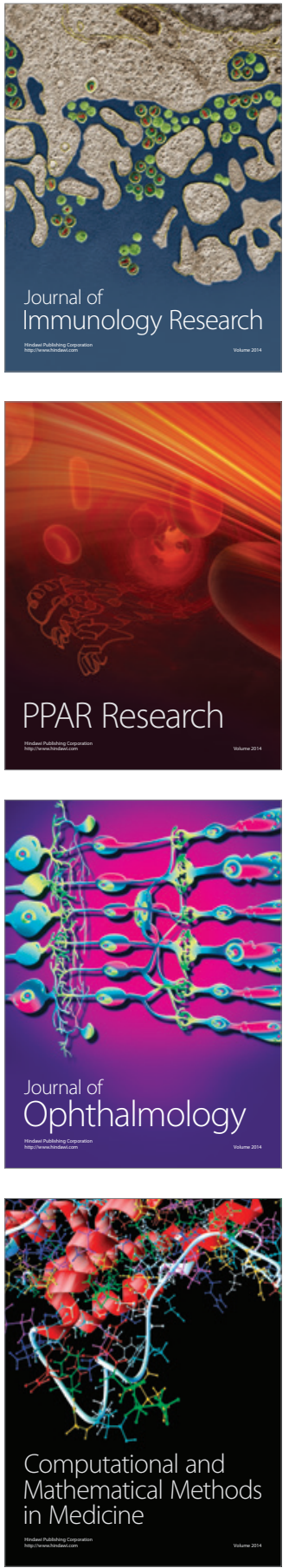

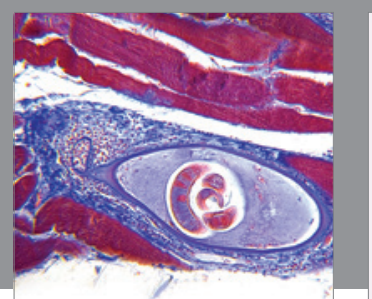

Gastroenterology Research and Practice
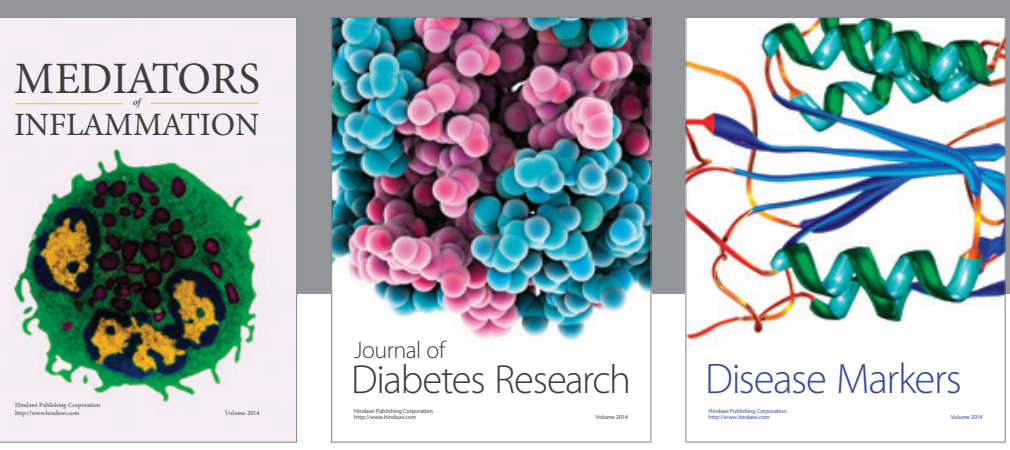

Disease Markers

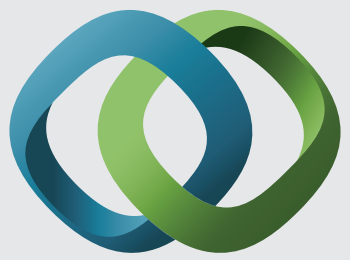

\section{Hindawi}

Submit your manuscripts at

https://www.hindawi.com
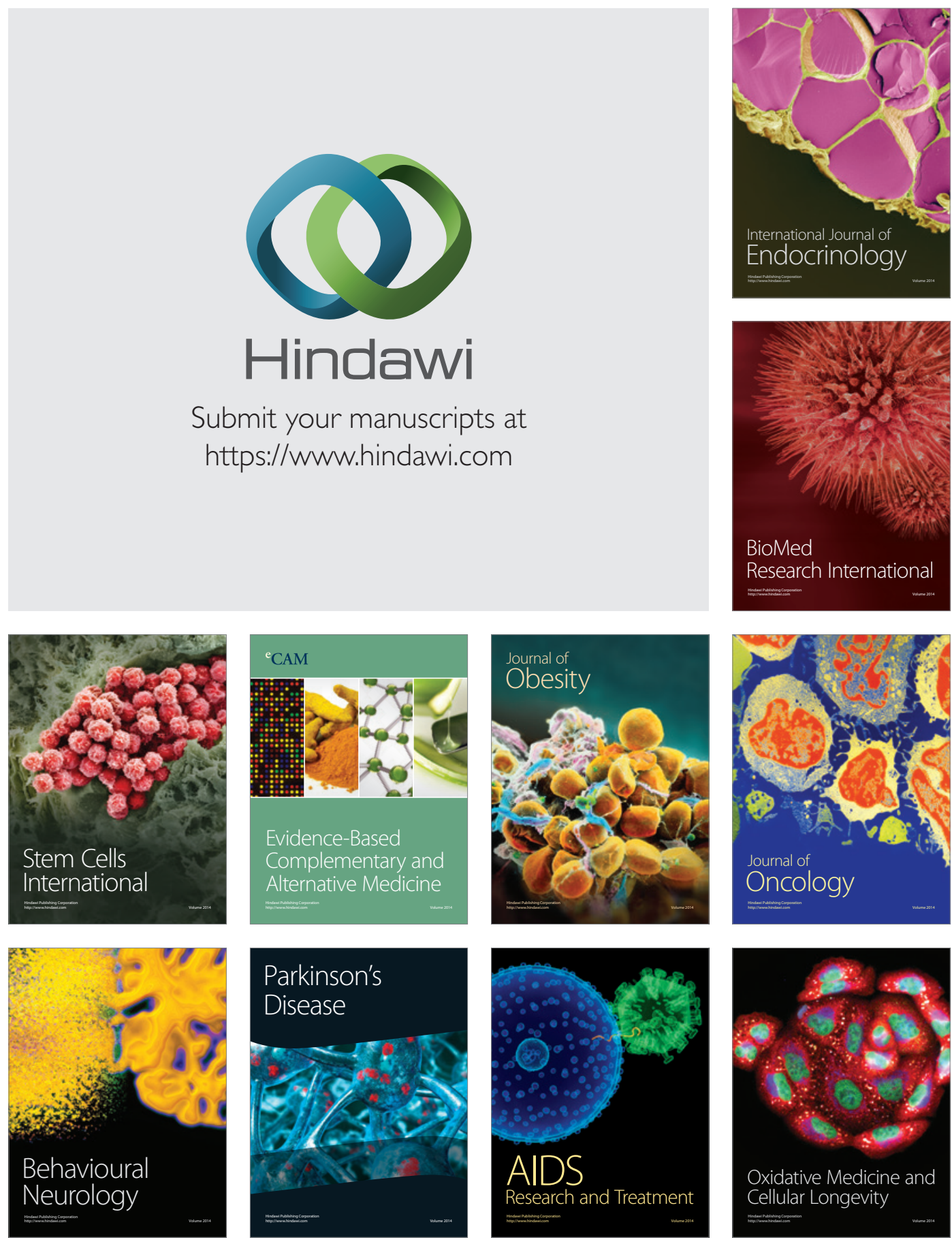